\title{
Capitalismo e Ascese: Elementos de Articulação Temática em Weber
}

Flávio Luiz Russo Riva

\section{Resumo:}

O objetivo do artigo é propor uma leitura da Ética protestante e o "espírito" do capitalismo que seja capaz de evidenciar tanto pressupostos metodológicos do autor (como, por exemplo, a centralidade do agente individual) quanto a sua idéia da autonomia das diferentes esferas da ação social. Originalmente escrito como trabalho final para matéria de introdução à sociologia de Weber, tenta contribuir para esclarecimento do problema mais geral da imputação causal histórica na famosa obra do autor, ressaltando aspectos considerados centrais.

Palavras-chave: Max Weber, esferas da ação, agente individual, idéias e interesses. 
Naturalmente, o primeiro caso foi o mais importante do ponto de vista histórico-desenvolvimental [entwicklungsgeschichtlich]. Pois já aqui, no limiar da sua aparição, mostrava a ascese a dupla face [Doppelgesicht]: afastamento do mundo, por um lado, e domínio do mundo em virtude das forças mágicas adquiridas mediante esse afastamento, por outro (WEBER, Consideração Intermediária).

$\mathrm{Na}$ apresentação a uma coletânea de textos de Weber, Cohn articula duas temáticas fundamentais na obra do autor: ao precisar o papel do conceito de "agente individual" no seu arcabouço teórico e metodológico mais geral, ele aponta para a relação do mesmo com a teoria da legalidade própria das esferas da ação social $^{\mathrm{I}}$. O objetivo deste artigo é estender a articulação a alguns pontos centrais da “Ética protestante e o ‘espírito' do capitalismo”. Não há nada de original nesta empreitada, já que o próprio trecho transcrito sugere essa aproximação. O ponto de partida para que se a realize pode ser o texto em que Weber esboça a distinção conceitual das esferas da existência, a Consideração Intermediária: Teoria dos graus e direções da rejeição religiosa do mundo ${ }^{2}$. Esse passo propicia uma entrada privilegiada na problemática da peculiaridade conceitual do protestantismo ascético, tal como ela é exposta na Ética... . Os parágrafos finais apresentam alguns comentários sobre essa aproximação, e tentam relacioná-la às temáticas referidas nessa introdução.

A Consideração Intermediária é um texto que integra o amplo campo do que Weber considerava como sociologia da religião; no entanto, ele frisou em

I "A importância da referência ao agente individual, nesse ponto, consiste em que ele é a única entidade em que os sentidos específicos dessas diferentes esferas de ação estão simultaneamente presentes e podem entrar em contato. Ou seja, se as diversas esferas da existência correm paralelas, movidas por suas 'legalidades próprias' e se está afastada a idéia de alguma delas ser objetiva e efetivamente determinante em relação às demais, a análise das relações entre elas (ou melhor, entre seus sentidos) só é possível com referência a essa entidade que as sustenta pela sua ação e é a portadora simultânea de múltiplas delas: agente individual. Portanto, não existem vínculos 'objetivos' entre esferas de ação; só vínculos 'subjetivos', isto é, que passam pelos sujeitos-agentes. Assim, toda a análise weberiana das afinidades ou tensões entre o sentido da ação religiosa e o sentido da ação econômica implica serem tomados os agentes individuais (que são simultaneamente portadores de sentidos econômicos e religiosos) como ponto de referência". (COHN, I979, p.29).

2 WEBER, M. Zwischenbetrachtung: Theorie der Stufen und Richtungen religiöser Weltablehnung. In: Gesammelte Aufsätze zur Religionssoziologie I. Tübingen: J.C.B. Mohr (Paul Siebeck), I988, 9ª Aufl., pp. 536-576. A tradução dos trechos lançou mão a todo instante da versão espanhola e a sua interpretação seguiu as indicações (WAIZBORT, I995). 
uma passagem fundamental que seu objetivo era oferecer uma "contribuição à tipologia e sociologia do próprio racionalismo" (Idid., p. 537) . A maneira específica pela qual essas duas dimensões do texto se articulam pode ser resumida em algumas linhas. Weber pretende "se voltar [...] para as relações de tensão entre mundo e religião" (Ibid., p. 540) para apreender a maneira pela qual o caráter das esferas da existência (familiar, econômica, política, estética, erótica e intelectual) e a sua autonomização geram tensões agudas com a esfera religiosa. "O 'mundo' pode entrar em conflito com postulados religiosos a partir de diferentes pontos de vista" (Ibid., p. 567) e as tensões geradas nesse conflito dependem do grau e da direção específica da autonomização das diferentes esferas da existência. É nesse sentido que o título do texto deve ser compreendido: trata-se de uma teoria dos graus e direções, que tenta "dar conta de um fenômeno multifacetado, que compreende racionalizações divergentes tanto nas suas orientações como nas suas intensidades" "(WAIZBORT, I995, p.29). Como não é possível dar conta da integridade do texto nesta curta exposição, o que importa por ora é ir ao trecho em que Weber trata mais especificamente da relação entre as esferas econômica e religiosa.

$\mathrm{O}$ autor mostra ali de que maneira o desenvolvimento da moderna economia capitalista faz com que ela entre em tensões progressivas com a ética da fraternidade religiosa. Isto ocorre principalmente porque o impessoalismo do amor fraternal das comunidades religiosas constituídas sob o signo afetivo do sofrimento entra em conflito com o impessoalismo não-fraternal característico do cosmos econômico societário ${ }^{4}$. Weber aponta algumas manifestações desse conflito histórico, como o preceito católico do "Deo placere non potest" e a ascese monástica, marcada pela rejeição ampla de qualquer possessão além do absolutamente imprescindível. Assim, a tensão entre esferas de valor parece encontrar aqui uma realização exemplar. No final desse trecho, encontra-se uma passagem fundamental:

3 Para uma definição sumária dos termos deste complexo processo, é possível recorrer a TENBRUCK, I980.

4 Ainda no próprio texto: "Assim como a ação racional econômica e política segue suas legalidades próprias, qualquer ação racional dentro do mundo encontra-se inescapavelmente ligada às condições 'alheias-àfraternidade' [brüderlichkeitsfremden] do mundo, que devem servir-lhe de meios ou fins - e, com isso, ela entra de algum modo em tensão com a ética da fraternidade". Nesse sentido, Habermas fala dessa tensão em termos de um "conflito estruturalmente fundamentado na oposição entre fraternidade e não-fraternidade" (HABERMAS, I995, p.552) 
Para escapar da tensão em princípio e internamente [prinzipiell und innerlich], havia apenas dois caminhos consequentes. Primeiro, o paradoxo da ética profissional puritana, que, enquanto religiosidade de virtuoses, renunciou ao universalismo do amor, objetivou [versachlichte] racionalmente toda atividade no mundo como um serviço à vontade positiva de Deus - que, ainda que totalmente incompreensível em seu significado último, era, mesmo assim, reconhecível - e como uma comprovação [Erprobung] do estado de graça, e que, com isso, aceitou a objetivação [Versachlichung] do cosmos econômico (depreciado juntamente com todo o mundo por ser corrompido e dizer respeito à criatura [kreatürlich]) aceito como querido por Deus e como material para o cumprimento do dever. Tratava-se, em última instância, da renúncia em princípio [prinzipiell] à salvação como um objetivo alcançável pelo homem e por todo homem, em favor da graça infundada, mas sempre estritamente particular. Em verdade, esse ponto de vista da não-fraternidade [Unbrüderlichkeit] não era mais uma autêntica 'religião de salvação (WEBER, 2004).

Como a indicação de Weber é clara, resta relacioná-la ao tema mais específico da Ética...(WEBER, 2004). O primeiro capítulo da segunda parte trata dos "fundamentos religiosos da ascese intramundana". O autor se propõe a avaliar ali a maneira pela qual o dogma da predestinação se pôs historicamente ${ }^{5}$. Para tanto, ele precisa atentar para a peculiaridade das representações religiosas que subjazem às éticas do calvinismo e do luteranismo, com o objetivo de "rastrear aqueles estímulos psicológicos [...] que davam a direção da conduta de vida e mantinham o indivíduo ligado nela"(WEBER, 2004, p.89). Weber expõe a maneira pela qual o referido dogma perde importância no curso da atividade de Lutero, e de que maneira ele aumenta em significação no desenvolvimento doutrinário de Calvino. A formidável coerência conceitual com que se elabora a doutrina calvinista é também sinal de que ela representa a conclusão do processo histórico-desenvolvimental de desencantamento do mundo: o indivíduo, em sua solidão interior, não conta com qualquer tipo de mediação para a busca da salvação - nas palavras do autor, trata-se da "supressão absoluta da salvação eclesiástico-sacramental" (Ibid., p.95).

5 A compreensão integral deste processo dependeria, na realidade, de um exame cuidadoso do texto "'Kirchen' und 'Sekten' in Nordamerika. Eine kirchen- und sozialpolitische Skizze" ["'Igrejas' e 'seitas' na América do Norte. Um esboço de política sócio-eclesial"] e de sua versão mais nova e aumentada "Die protestantischen Sekten und der Geist des Kapitalismus" ["As seitas protestantes e o espírito do capitalismo"], respectivamente de 1906 e 1920. No entanto, esse exame extrapolaria os objetivos desse curto texto. Para uma introdução à centralidade da problemática apresentada nesses textos para a compreensão da "Ética..." ver GROSSEIN, I996, pp. 74-77. 
Weber tenta esclarecer em seguida quais os caminhos tomados individualmente para que fosse suportada uma doutrina como essa, em uma época de intensa religiosidade. $\mathrm{Na}$ realidade, a idéia da predestinação não redunda num fatalismo intransponível, sua consequência lógica: "o efeito psicológico foi exatamente o contrário, e isso porque interveio a idéia da "comprovação"” (Ibid., p.2I8). Weber elucida de que maneira ela surge, ao mostrar como a prática da cura de almas lidou com os tormentos incontornáveis gerados pelo dogma na atividade de acompanhamento pastoral. Se, por um lado, ela associou a convicção da certitudio salutis a um dever para todo aquele em que a graça atua de maneira suficiente ela aconselhou, por outro, o trabalho no mundo como forma de adquirir a sua certeza subjetiva em toda a sua clareza. Os dois tipos de aconselhamento estão, aliás, ligados de maneira coerente ao sistema conceitual do calvinismo, e não poderiam ter surgido no luteranismo em razão de sua concepção manifestamente mística da experiência religiosa - ligada, portanto, a um "ter", mais do que a um "agir". O fato de que o calvinista guiado pela práxis pastoral da cura de almas "cria" individualmente sua certitudio salutis por meio de uma "auto-inspeção sistemática que a cada instante enfrenta a alternativa: eleito ou condenado?" (Ibid., p.IO5) é de importância central: é no seio desse conjunto de idéias religiosas específicas que primeiro se associou historicamente um interesse à condução sistemática da vida mundana, de modo a gerar os estímulos e prêmios psicológicos que estavam na base da ascese intramundana - marcada por "uma conformação racional de toda a existência, orientada pela vontade de Deus" (Ibid., p.I39). É nesse sentido que Weber fala, ainda nesse capítulo, do tema que o entretém: "aquelas conexões [...] entre as idéias de predestinação e as de comprovação alicerçadas no interesse em obter subjetivamente a certitudio salutis" (Ibid., p.II7).

É a respeito dessas conexões que fala o autor no trecho transcrito da "Consideração Intermediária". Enquanto religião de rejeição do mundo, o calvinismo dirige uma atenção incansável ao Outro Mundo e aos desígnios insondáveis do decretum horribile, que escolhe alguns homens para a salvação. No entanto, a idéia de comprovação que intervém no seio dos reformados por meio da prática da cura de almas introduz a ascese "na vida mundana de todo dia" (Ibid., p.I39), objetivando "toda atividade no mundo como um serviço à vontade positiva de Deu"6. A referência às categorias sociológicas fundamentais do autor permite dizer que o indivíduo - detentor de um interesse "focalizado unicamente em Deus, não nos seres humanos" (Ibid., p.94) - age com referência a um sentido

6 Ver trecho transcrito, supra. 
(Id., 2004b, pp3-35) propriamente religioso: com a representação subjetiva de um valor próprio à esfera religiosa. Afinal, ele concebe o curso e os resultados de sua ação como índice da salvação. É esse sentido subjetivamente representado que torna efetiva a ação; no entanto, essa conexão de sentido específica não deixa de gerar seus efeitos nas outras esferas da existência: a "objetivação do cosmos econômico"7 é um desses efeitos, gerados justamente porque essa conexão também aparece historicamente em ações economicamente orientada ${ }^{8}$. Essas considerações tornam mais claro o esforço final da Ética... em associar as concepções religiosas fundamentais do protestantismo ascético e as formulações mais claras da conduta de vida econômica, por meio da leitura dos textos teológicos que nasceram da prática de cura de almas. Assim, o que importa frisar é que a significação histórica da peculiaridade conceitual do protestantismo ascético se encontra justamente no fato de ele criar "as condições necessárias para a formação de uma base motivacional da ação racional referente a fins na esfera do trabalho social" (HABERMAS, I995, p. 3I4). Todos esses desdobramentos ganham toda a clareza quando aparecem relacionados ao conteúdo da Consideração... .

O reformado pode agir no mundo com vistas a um interesse religioso sem entrar em conflito com a ética religiosa de fraternidade - as condições "alheiasa-fraternidade"9 desse mundo podem figurar-lhe como meios e fins para a salvação, "sempre estritamente particular" ". Se isso estiver certo, as afinidades entre aspectos do protestantismo ascético e aspectos do ethos peculiar que o autor chama de "espírito' do capitalismo" podem ser encaradas como traços de um abrandamento da aguda tensão ${ }^{\text {II }}$ entre as esferas econômica e religiosa abrandamento que só pôde ocorrer nos portadores históricos do protestantismo ascético, na medida em que as representações subjetivas de suas ações e seus

\footnotetext{
7 Ver trecho transcrito, supra.

8 'Uma ação será denominada 'economicamente orientada' na medida em que, segundo seu sentido visado, esteja referida a cuidados de satisfazer o desejo de obter certas utilidades". A ação profissional no mundo certamente figura como uma ação desse tipo. O conjunto central de problemas da Ética... está, então, perfeitamente ajustado ao domínio científico que Weber atribuia à ciência econômico-social no ensaio metodológico de I905: a "pesquisa científica do significado cultural geral da estrutura socioeconômica da vida social humana" (WEBER, 2004b, p.38). O tímido aviso de um importante intérprete da obra de Weber foi a origem do esforço de aproximação presente nessa nota: "It has not been sufficiently appreciated that while the Objectivity essay was concerned with general methodological questions, it was also written essentially as a methodological justification for the PE [The prothestant ethic and the spirit of capitalism]" (TENBRUGK, I980, p.347).

9 Ver nota 7, supra.

IO Ver trecho transcrito, supra.

II Cohn afirma em outra ocasião que o par analítico tensão/afinidade é pertinente para falar de relações entre significados de ações que normalmente se atribui a esferas autônomas da existência. Nesse sentido, voltamos ao ponto de partida, com o auxílio do mesmo comentador.
} 
respectivos cursos deixaram de carregar esse teor de tensão. Nesses portadores, a ascese pôde gerar os efeitos históricos de que se ocupa o autor. Ao enquadrar a Ética... no referencial teórico e conceitual da Consideração Intermediária o caráter paradoxal desses efeitos também se torna mais inteligível. Não é outro o significado da "rija crosta de aço" (WEBER, 2004, p.I65) que pesa sobre os ombros dos indivíduos na relação com os bens deste mundo depois do impulso inicial de uma ética voltada essencialmente para o Outro Mundo; parece estar-se diante, então, de uma tensão da qual se "escapa", mas que volta a se intensificar sob uma nova forma - forma que o temor de John Wesley, fundador do metodismo, resume de maneira exemplar: "Temo: onde quer que a riqueza tenha aumentado, na mesma medida haja decrescido a essência da religião" (WESLEY apud WEBER, 2004, p.I59). A "dupla face" da ascese mostra ser, mesmo, uma "face de Jano" - como sugeriu a tradução inglesa do trecho da epígrafe, no que foi seguida pelas edições brasileiras do texto, que nela se basearam.

\section{Referências Bibliográficas:}

COHN, G. "Introdução". In: (Org.) Max Weber. São Paulo: Ática, I979, pp. 7-37.

. "Alguns problemas conceituais e de tradução em Economia e Sociedade". In: WEBER, M. Economia e Sociedade. Fundamentos de sociologia compreensiva. São Paulo: Ed. UnB, 2004, pp. xiii-xv.

"Apêndice: Sobre o significado da racionalização". In: Crítica e resignação. Max Weber e a teoria social. São Paulo: Martins Fontes, 2003, pp. $227-242$

GROSSEIN, J-.P. "Présentation". In: Sociologie des religions. Paris: Gallimard, I996, pp. 5I-II8

HABERMAS, J. "Max Webers Theorie der Rationalisierung". In: Theorie des kommunikativen Handelns. Band I: Handlungsrationalität und gesellschaftliche Rationalisierung. Frankfurt/M: Suhrkamp, I995, pp. 225-365.

TENBRUCK, F. H. "The problem of thematic unity in the works of Max Weber". In: The British Journal of Sociology. Vol. 3I, No. 3, I980, pp. 3I6-35I. 
WAIZBORT, L. 'Introdução". In: Os fundamentos racionais e sociológicos da música. São Paulo: Edusp, I995, pp. 23-5I.

WEBER, M. A "objetividade" do conhecimento nas ciências sociais. São Paulo: Ed. Ática, 2006.

. A ética protestante e o "espírito do capitalismo". São Paulo: Companhia das Letras, 2004.

. "Teoria das categorias sociológicas". In: Economia e Sociedade.

Fundamentos de sociologia compreensiva. São Paulo: Ed. UnB, 2004a, pp. 3-35.

. "Categorias sociológicas fundamentais da gestão econômica". In: Economia e Sociedade. Fundamentos de sociologia compreensiva. São Paulo: Ed. UnB, 2004b, pp. 37-I38.

" "Zwischenbetrachtung: Theorie der Stufen und Richtungen religiöser Weltablehnung”. In: Gesammelte Aufsätze zur Religionssoziologie I. Tübingen: J.C.B. Mohr (Paul Siebeck), I988, 9a Aufl., pp. 536-576. [trad. port.: _. "Rejeições religiosas do mundo e suas direções". In: Ensaios de Sociologia. Rio de Janeiro: Zahar Editora, I963, pp.37I-4I2; trad. ingl.: . "Religious rejections of the world and their directions" In: From Max Weber: Essays in Sociology. New York: Oxford University Press, pp. 323-359.]

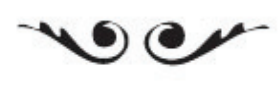

Flávio Luiz Russo Riva é graduando em Giências Sociais pela USP.

E-mail: flavinhoriva@hotmail.com 